\title{
ARTIGOORIGINAL
}

\section{Uma extensão ao modelo de emoções e de personalidades baseado em sistemas multiagentes utilizando distribuição normal, lógica Fuzzy e matemática intervalar}

\author{
An extension to emotions and personalities model based on \\ multi-agent systems using normal distribution, Fuzzy logic and \\ interval mathematics
}

\author{
Christian Pereira Tavares ${ }^{1}$, Cleo Zanella Billa ${ }^{\oplus, 1}$, Diana F. Adamatti ${ }^{\varpi}, 1$ \\ ${ }^{1}$ Centro de Ciências Computacionais - Universidade Federal do Rio Grande (C3/FURG) \\ *\{christiantavarest, cleo.billa, dianaada\}@gmail
}

Recebido: 10/04/2019. Revisado: 29/02/2020. Aceito: 21/03/2020.

\begin{abstract}
Resumo
Este artigo consiste em uma extensão ao modelo de emoções e de personalidades baseado em sistemas multiagente. A inicialização deste modelo tem valores fixos para a personalidade e a influência da personalidade sobre a emoção. Este valor deve variar no intervalo [0;1], sendo que o valor zero representa quase inexistência da determinada personalidade ou influência sobre as emoções, e um, a presença total. Portanto, sendo fixado um valor na inicialização do modelo, o mesmo não será capaz de mostrar precisamente o modo que estas emoções e personalidades influenciam nas decisões do ser humano, uma vez que cada indivíduo não possui a capacidade de uma ponderação quantitativa de suas emoções e personalidade. Para tornar o modelo uma solução mais próxima do comportamento humano, foram estudadas técnicas para resolver o problema da inicialização fixa na influência da personalidade sobre a emoção. Para isso, o artigo apresenta três técnicas diferentes de inicialização: Distribuição Normal, Lógica Fuzzy e Matemática Intervalar. Pelos resultados obtidos, a lógica Fuzzy apresentou-se como a técnica mais constante para todos os cenários de teste. O intuito da utilização destas técnicas consiste em poder ter uma visão mais ampla e melhor apresentada de diferentes resultados de saída do modelo. Além disso, possibilita uma comparação com os resultados do modelo original, para tentar obter uma melhor representação do modelo humano, podendo-se obter um modelo mais robusto e aplicável a outros domínios.
\end{abstract}

Palavras-Chave: Emoções; Lógica Fuzzy; Matemática Intervalar; Personalidade; Sistemas Multiagente

\section{Abstract}

This paper consists of an extension to the model of emotions and personalities based on multiagent systems. The initialization of this model has a fixed values, assigned for the personality and the influence of the personality on the emotion. This value should vary in the interval [0;1], where the value zero represents almost nonexistence of the given personality or influence on the emotions, and one, the total presence. Therefore, when a value is set at the initialization of the model, it will not be able to show precisely the way these emotions and personalities influence the decisions of the human being, since each individual does not possess the ability to quantitatively weigh their emotions and personality. For this, the paper presents the initialization using three different techniques: Normal Distribution, Fuzzy Logic and Interval Mathematics. Basing in our results, Fuzzy Logic was the more constant technique in all tested scenarios. The purpose of using these techniques is to be able to have a broader and better view of different model output results. In addition, it allows a comparison with the results of the original model, in order to try get a better representation of the human model and to have a more robust model that could be applied in other domains. 


\section{Introdução}

Os seres humanos distinguem-se dos outros animais pela capacidade que tem de agir com racionalidade, capacidade mental e adquirir conhecimento. Por esta razão, são alvo de vários estudos a fim de buscar um entendimento sobre o seu comportamento (de Almeida Limeira et al., 2016).

O estudo do comportamento humano tem como objetivo ajudar a entender as ações realizadas pelas pessoas em determinadas situações, bem como os motivos que condicionam tais ações, e todas as possíveis alterações que o meio e as relações sociais, ao longo da vida, proporcionam a cada indivíduo. O comportamento pode ser descrito basicamente como o que o indivíduo faz com relação ao meio em que é inserido e em relação aos demais indivíduos (da Conceicao, 2009). Nesses termos, as ações tomadas pelo ser humano são baseadas fortemente em sua personalidade, modo de determinar os padrões de pensar, sentir e agir, e em suas emoções, associada ao temperamento, personalidade e motivação.

Para modelar o estudo do comportamento humano, levando em conta sua personalidade e suas emoções, é aconselhável fazer o uso de simulações computacionais. Estas simulações são muito comuns para diversos fins, como simulações físicas, matemáticas, químicas e, da mesma maneira, simulações sociais. Sistemas multiagente é uma abordagem muito utilizada e que melhor se encaixa para realizar simulações sociais (Bercht, 2001, Gilbert and Troitzsch, 2005). Esta abordagem é uma técnica muito eficiente para utilização de simulações, onde há a necessidade de simular diversas instâncias que interagem e se comportam de forma heterogênea. Contudo, por mais complexas e melhores que estas simulações sejam, elas acabam se tornando apenas uma representação simplificada do modo que ocorre na natureza. Existem muitas definições diferentes do que são emoções, de quais são as emoções sentidas pelo ser humano, ou quais são as emoçõ̃es essenciais. Por ter essa grande complexidade, acaba se tornando difícil modelar de forma completa todas as emoções sentidas por um indivíduo em uma simulação computacional. De forma semelhante ocorre com a personalidade, a complexidade sobre $\mathrm{o}$ assunto é grande e o conhecimento é limitado. Desta forma, o melhor modo de trabalhar com ambas, é usando suas simplificações (Egges et al., 2004).

Modelar o mais próximo possível o comportamento humano através de métodos computacionais é um tema bastante pesquisado, seja em aplicações com inteligência artificial em jogos, seja para softwares que se adaptam ao usuário. Diversos trabalhos vem tentando apresentar de forma mais próxima a realidade modelos de agentes que façam uso de emoções e personalidade ((McDuff and Czerwinski, 2018), (Pudane et al., 2017), (Heudin, 2018)).

Como existem estas necessidades, existem também definições de modelos teóricos, que tentam simular ou imitar como ocorre na natureza. Dentre estes modelos existem os modelos de emoções como o OCC (Ortony et al., 1988), Modelo de Ekman (Ekman, 2005), Modelo de Kort e Reilly e Picard (Kort et al., 2001). Para modelagem de personalidade pode-se citar o modelo OCEAN (Tupes and Christal, 1961, Digman, 1990, Costa and McCrae, 2008, Goldberg, 1993) (também conhecido como Big-Five), modelo hipostático da personalidade Tapu (2001) e modelo de personalidade de Millon (Millon et al., 1994).

O OCC é um modelo definido por psicólogos, o qual engloba 22 emoções, que são geradas a partir de estímulos positivos ou negativos, de acordo com determinados tipos de eventos. Enquanto o OCEAN é um modelo de personalidade definido por pesquisadores independentes, que perceberam que os seres humanos possuem cinco traços de personalidade bem definidos e que a personalidade de qualquer humano pode ser bem representada dando um peso para cada um destes traços.

Deste trabalho, utilizam-se os modelos OCC e OCEAN. O modelo OCC é muito utilizado computacionalmente, pois é um modelo bem documentado, com explicações e especificações das variáveis do modelo e as variáveis de ativação das emoções. O modelo OCEAN de personalidade, é um modelo de fácil implementação computacional e pode se adaptar facilmente a diversas aplicações, pois representa com pesos o traço de personalidade de uma pessoa.

Embora o modelo OCC seja muito utilizado para representar a influência das emoções computacionalmente em agentes, possui o problema de, a partir de um mesmo estímulo, as emoções sentidas serão sempre a mesma. Isso faz com que o modelo se distancie do comportamento humano, onde podem ocorrer diferentes reações emocionais para um mesmo estímulo sentido. Por isto, foi utilizado o modelo OCEAN, o qual interfere a forma com que a emoção é gerada, fazendo com que a emoção sentida seja determinada não apenas pelo evento sentido pelo agente, mas também pela sua personalidade.

Tanto personalidade como emoções podem influenciar nas ações que um indivíduo toma. O trabalho proposto por (Urban Filho, 2015, Urban Filho and Adamatti, 2018) propõe uma construção da integração entre emoções e personalidade, de forma que uma possa influenciar na outra e ambas influenciam na tomada de decisão final, inserida em um ambiente multiagente, para que neste ambiente sejam feitas simulações que envolvam a tomada de decisão entre agentes.

Contudo, esse modelo proposto possui em sua inicialização um valor fixo na influência da personalidade sobre cada emoção. Esse valor atribuído está presente no intervalo entre zero e um, sendo zero quase inexistente a determinada influência da personalidade sobre a emoção e um a influência total. Portanto, sendo fixado um valor na inicialização do modelo, o mesmo não será capaz de mostrar precisamente o modo que estas emoçõ̃es e personalidades influenciam nas decisões do ser humano, onde cada indivíduo não possui a capacidade de uma ponderação quantitativa de suas emoções e personalidade.

Pensando em tornar esse modelo uma solução ainda mais próxima do comportamento humano, uma extensão do modelo de emoções e personalidades propostas por (Urban Filho, 2015) foi realizada. A utilização de 
modelos não-determinísticos pode solucionar o problema da inicialização fixa da influência da personalidade sobre as emoções. Para isso, o desejo de que as variáveis inicializem com um intervalo de valores e desse intervalo possa ser retirado um valor escolhido a partir das técnicas não-determinísticas, usando-o para a inicialização do modelo. Deste modo, o modelo irá se assemelhar ao comportamento humano, onde não possuímos a capacidade de ponderação quantitativa de nossas emoções e personalidade.

Neste trabalho são utilizados três modelos nãodeterminísticos para a inicialização da influência da personalidade sobre as emoções: Distribuição normal, um modelo que descreve o comportamento de vários fenômenos aleatórios, sua escolha foi feita por essa técnica ser utilizada em muitas aplicações em matemática, em ciências exatas, ou em ciências humanas e sociais; Lógica Fuzzy, capaz de capturar informações vagas, chamadas de variável linguística, e as converte para um formato numérico, de fácil manipulação, sua escolha foi devido ao fato de ser um modelo fortemente utilizado na computação e ser bastante informações e documentação sobre ela; e, por fim, Matemática intervalar, onde considera um conjunto de métodos para manipulação de intervalos numéricos que aproximam dados incertos.

Para avaliar os modelos assim propostos, é feita uma comparação entre os três modelos não-determinísticos e também a comparação entre estes três modelos, com os resultados obtidos no modelo original, a fim de poder determinar se realmente o modelo torna-se nãodeterminístico, assemelhando-se ao comportamento humano, e observando se a média de vida do agente nos modelos não-determinísticos foi maior.

Este artigo está estruturado em 6 secções. Na Seção 2 é apresentada revisão bibliográfica necessária para entendimento do estudo realizado. A Seção 3 apresenta o modelo base, proposto por (Urban Filho, 2015). Na Seção 4 é mostrada a implemnetação dos modelos não-determinísticos utilizados. A Seção 5 apresenta a análise dos resultados obtidos e finalmente, na Seção 6 estão as conclusões e trabalhos futuros.

\section{Revisão de bibliográfica}

\subsection{Emoções}

As emoções possuem um grande impacto na tomada de decisões, ações, memória, atenção, pois elas são consideradas a regra central de nossas vidas (Gratch and Marsella, 2001). Por este motivo, existem diversas propostas para a modelagem de emoções a fim de tentar uma explicação melhor de como estas funcionam. Estas propostas oferecem o modelo básico para que emoções sejam simuladas computacionalmente (Gratch and Marsella, 2001). Dependendo da aplicação, alguns modelos se encaixam melhor do que outros.

Simulação de emoções em máquina não é uma tarefa fácil de ser modelada, pois em processos que as emoções exercem um papel muito importante, como processos de tomada de decisão, são influenciados por diversos fatores, tanto sociais quanto fisiológicos, que tornam esse processo de modelagem e simulação bastante complexo (Marsella et al., 2010).

Muitas das dificuldades ocorrem pelo fato de que as emoções são o centro das motivações humanas, sendo tanto precursor quanto resultado final em muitos empreendimentos, isto é, as emoções interferem em nosso comportamento, ações, na forma como nos relacionamos com outras pessoas (Bercht, 2001).

Quando o assunto é o funcionamento das emoções, se deve levar em conta duas características: as emoções são processos fisiológicos de difícil mensuração, são coisas que sentimos; e, emoções são geradas por estímulos. Entretanto, é impossível afirmar que um mesmo estímulo irá gerar a mesma emoção em dois indivíduos diferentes. Isto se deve a diversos fatores que, em resumo, definem cada pessoa como um ser diferente (Pudane et al., 2017).

Para a aplicação proposta por Urban Filho (2015), o modelo utilizado é o OCC (acrônimo de seus criadores Ortony, Clore e Collins)(Ortony et al., 1988), pois o modelo oferece uma estrutura para se descobrir quais emoções podem ser geradas a partir de um determinado evento em um ambiente qualquer.

\subsubsection{Modelo OCC}

O modelo OCC é um modelo de emoções onde a partir de estímulos gerados em um ambiente arbitrário, este modelo é capaz de identificar quais emoções seriam geradas, dentro de um conjunto pré-determinado de emoções. Este é um dos modelos mais utilizados no ramo da computação, seja para adicionar emoções a agentes artificiais ou para se trabalhar com a tomada de decisão influenciada pelas emoções (Ortony et al., 1988).

O modelo é baseado no princípio de diferenciação entre reações de valência positivas e negativas, ou seja, a partir de um estímulo do ambiente, variáveis são atribuídas de forma a determinar se o evento proporciona sentimentos positivos ou negativos para o indivíduo modelado. O modelo OCC apresenta uma divisão das emoções em três categorias principais, explicadas a seguir e visualizadas na Fig. 1.

Event-based Emotions: são emoções que decorrem de eventos com outros indivíduos ou com o próprio indivíduo. As emoções envolvidas com os outros indivíduos estão: Happy-For, Pity, Gloating e Ressentment; e com os próprios indivíduos estão: Joy, Distress, Satisfaction, Fears-Confirmed, Relief e Desapointment.

Agent-Based Emotions: são emoções que decorrem de ações com outros indivíduos ou com o próprio indivíduo. As emoções envolvidas com outros indivíduos estão: Admiration e Reproach; e com os próprios indivíduos estão: Pride e Shame.

Object-Based Emotions: são emoções direcionadas a objetos. São definidas duas emoções: Love e Hate.

A Tabela 1 apresenta um resumo das relações existentes entre cada emoção e as suas condições para o seu disparo no modelo OCC.

No modelo utilizado como base, as emoções Love e Hate foram desconsideradas, pois elas não possuíam um propósito na aplicação. Posteriormente, será explicado a importância e a função de cada emoção dentro do 


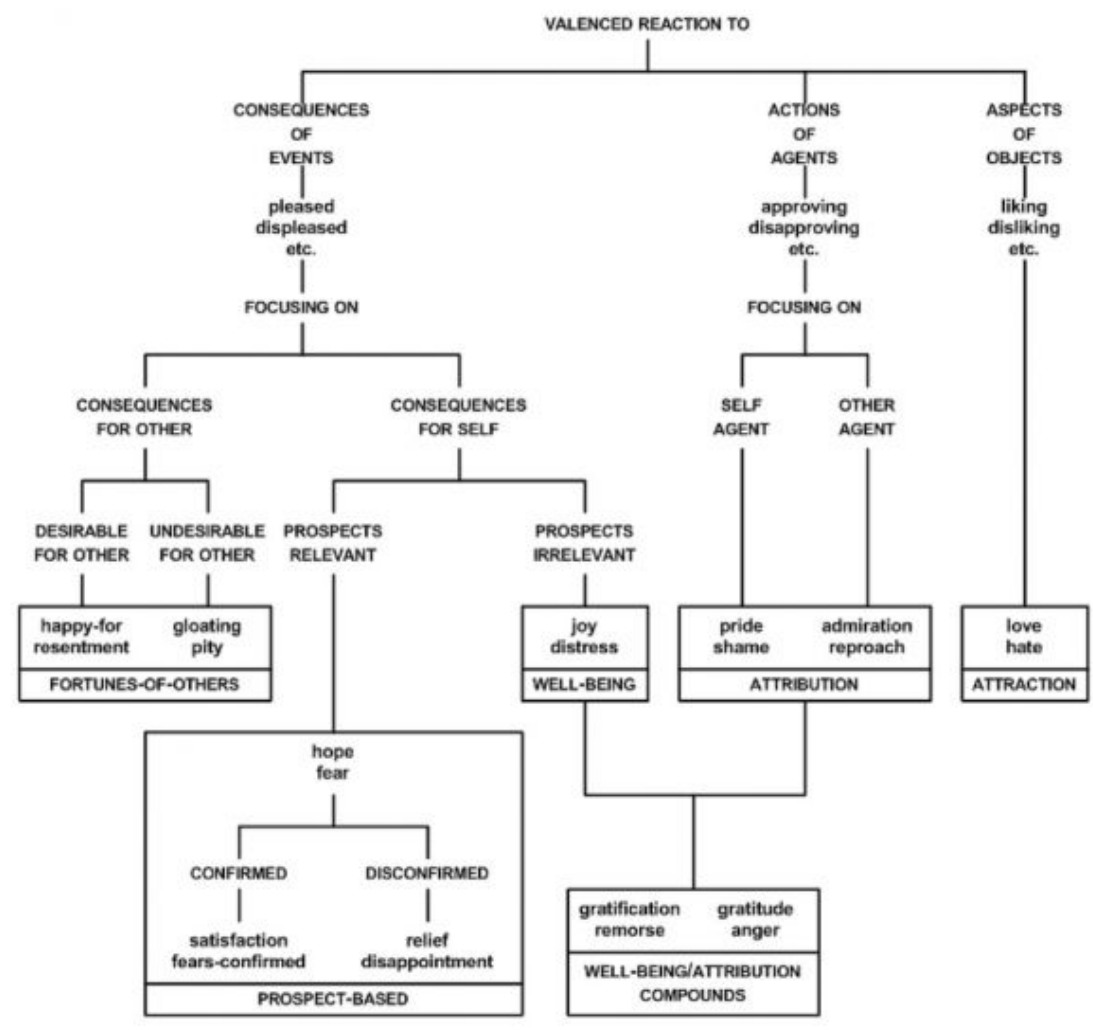

Figura 1: Modelo OCC, proposto por (Ortony et al., 1988), com suas divisões em eventos, agentes e objetos

modelo proposto.

\subsection{Personalidade}

Personalidade é o conjunto das características marcantes de uma pessoa, é a força ativa que ajuda a determinar o relacionamento das pessoas baseado em seu padrão de individualidade pessoal e social, referente ao pensar, sentir e agir. Pesquisadores e filósofos tentam, a muito tempo, definir o funcionamento da personalidade humana para suas reações adversas para uma mesma situação (Carver and Scheier, 2000).

Do mesmo modo que as emoções representam a integração de sentimentos, ação, avaliação e desejo em um determinado tempo e lugar, a personalidade é representada por estes componentes através da integração temporal e espacial (Egges et al., 2004).

\subsubsection{Modelo OCEAN}

O modelo OCEAN, também conhecido como Big Five, foi criado por um grupo de pesquisadores (Tupes and Christal, 1961, Digman, 1990, Costa and McCrae, 2008, Goldberg, 1993), onde estes definiram a personalidade humana como o conjunto de cinco grandes fatores. Atualmente, este conceito é amplamente usado nas diver- sas áreas do conhecimento.

Dos cinco fatores presentes, estão a abertura à experiência (Openness) que está relacionada ao interesse pela arte, emoção, aventura, ideias fora do comum, imaginação, curiosidade, e variedade de experiências; a Escrupolosidade (Conscientiouness) onde é medido o grau de concentração; Extroversão (Extroversion) onde é medida a sensação de bem-estar, o nível de energia e a habilidade nas relações interpessoais; Altruísmo (Agreeableness) é medido como nos relacionamos com os outros; e Neuroticismo (Neuroticism) onde é medido a instabilidade emocional.

Cada indivíduo possui um valor arbitrário, diferente em cada personalidade. Quanto maior for o seu valor, maior é o traço daquela personalidade no indivíduo e pelo mesmo motivo, quanto menor for o valor, menor é o traço daquela personalidade no indivíduo.

A Tabela 2 demonstra os cinco grandes fatores do OCEAN, melhor explicado, e o que eles representam em um indivíduo.

\subsection{Sistemas Multiagente}

Os Sistemas Multiagente (SMA) são uma subárea da Inteligência Artificial Distribuída (IAD), que diferen- 
Tabela 1: Emoções do Modelo OCC e suas condições

\begin{tabular}{|c|c|}
\hline Emoção & Condição \\
\hline Joy & (contente com) um evento desejável \\
\hline Distress & (descontente com) um evento indesejável \\
\hline Happy-for & (contente com) um evento que se presume desejável para outro indivíduo \\
\hline Pity & (descontente com) um evento que se presume indesejável para outro indivíduo \\
\hline Gloating & (contente com) um evento que se presume indesejável para outro indivíduo \\
\hline Resentment & (descontente com) um evento que se presume indesejável para outro indivíduo \\
\hline Hope & (contente com) a perspectiva de um evento desejável \\
\hline Fear & (descontente com) a perspectiva de um evento indesejável \\
\hline Satisfaction & (contente com) a confirmação da perspectiva de um evento desejável \\
\hline $\begin{array}{l}\text { Fears- } \\
\text { confirmed }\end{array}$ & (descontente com) a confirmação da perspectiva de um evento indesejável \\
\hline Relief & (contente com) a não confirmação da perspectiva de um evento indesejável \\
\hline Disappointment & (descontente com) a não confirmação da perspectiva de um evento desejável \\
\hline Pride & (aprovação de) uma ação louvável do próprio indivíduo \\
\hline Shame & (desaprovação de) uma ação condenável do próprio indivíduo \\
\hline Admiration & (aprovação de) uma ação louvável de outro indivíduo \\
\hline Reproach & (desaprovação de) uma ação condenável de outro indivíduo \\
\hline Gratification & $\begin{array}{l}\text { (aprovação de) uma ação louvável do próprio indivíduo e (estar contente com) um evento desejável } \\
\text { relacionado }\end{array}$ \\
\hline Remorse & $\begin{array}{l}\text { (desaprovação de) uma ação condenável do próprio indivíduo e (estar descontente com) um evento } \\
\text { indesejável relacionado }\end{array}$ \\
\hline Gratitude & $\begin{array}{l}\text { (aprovação de) uma ação louvável de outro indivíduo e (estar contente com) um evento desejável } \\
\text { relacionado }\end{array}$ \\
\hline Anger & $\begin{array}{l}\text { (desaprovação de) uma ação condenável de outro indivíduo e (estar descontente com) um evento } \\
\text { indesejável relacionado }\end{array}$ \\
\hline Love & (gostar de) um objeto atraente \\
\hline Hate & (não gostar de) um objeto desagradável \\
\hline
\end{tabular}

Tabela 2: Descrição do Modelo OCEAN (Openness, Conscientiouness, Extroversion, Agreeableness e Neuroticism)

\begin{tabular}{|c|c|}
\hline AN & escrição \\
\hline Openness & $\begin{array}{l}\text { Indivíduos com abertura à experiência geralmente são muito ativos, têm uma enorme inclinação } \\
\text { para a criatividade e estética, e são mais propensos a seguir os seus sentimentos internos. Estes } \\
\text { indivíduos são geralmente abertos a novos aprendizados, procuram novas habilidades e experiências. } \\
\text { Pessoas com um alto peso em Openness geralmente tem a "mente mais aberta" e "moderna" em } \\
\text { suas perspectivas em relação aos indivíduos que tem um valor baixo neste mesmo parâmetro. Tais } \\
\text { indivíduos são conservadores, relutantes a mudanças e tem uma abordagem mais tradicional para } \\
\text { com a vida. }\end{array}$ \\
\hline Conscient. & $\begin{array}{l}\text { Quando um indivíduo tem um valor alto de Conscientiousness ele é mais cauteloso e auto-disciplinado. } \\
\text { Não realiza ações por impulso, pensa antes de agir, age com consciência. Uma pessoa com esse } \\
\text { traço de personalidade é geralmente metódica e tende a se tornar perfeccionista em longo prazo. } \\
\text { Pessoas com um valor alto em Conscientiousness são mais orientados de forma pró-ativa, objetiva e } \\
\text { auto-disciplinada. Eles se esforçam muito para alcançar metas e objetivos dentro do prazo estipulado. }\end{array}$ \\
\hline Extra & $\begin{array}{l}\text { Quando um indivíduo tem um valor alto no peso Extraversion, ele pode ser definido como um ser } \\
\text { extrovertido. De maneira oposta, quando há um valor baixo, ele pode ser referenciado como um } \\
\text { indivíduo introvertido. Um ser extrovertido se preocupa mais com o mundo a sua volta, é um ser que } \\
\text { tem mais tendências a interagir com as pessoas ao redor, é mais comunicativa e não gosta de passar } \\
\text { o tempo sozinho. Gosta de festas, convenções sociais e de conhecer pessoas. Já um ser introvertido é } \\
\text { o oposto, é um indivíduo mais "fechado", se preocupa mais com a própria vida e pouco com o que } \\
\text { acontece ao redor. Prefere ficar em casa em vez de sair com outras pessoas. Fala menos e portanto } \\
\text { tende a ter uma quantidade menor de amigos. }\end{array}$ \\
\hline Agreeab & $\begin{array}{l}\text { Agreeableness é um traço de personalidade que interfere de forma positiva em como o indivíduo se } \\
\text { adapta à algumas situações, sendo que um indivíduo com um valor alto neste fator tende a enfrentar } \\
\text { e aceitar bem mudanças que eventualmente ocorrem. É um indivíduo mais amigável e bondoso, está } \\
\text { sempre pronto para ajudar os outros. Já indivíduos com valor baixo tem mais dificuldades em ajudar } \\
\text { os outros e podem ser um pouco indesejados. }\end{array}$ \\
\hline Neurotici & $\begin{array}{l}\text { Uroticism é um traço no qual os indivíduos são mais propensos a terem pensamentos negativos, } \\
\text { s como ansiedade, raiva, inveja, culpa e medo. Tendem a ser mais depressivos, a olhar para o lado } \\
\text { im das coisas e a lidar mal com situações caóticas e com o estresse. }\end{array}$ \\
\hline
\end{tabular}

temente da Inteligência Artificial clássica, é capaz de simular um comportamento entre vários indivíduos, seu comportamento social, e as iterações que existem entre eles, podendo ser analisado tanto o nível micro 
(indivíduo) quanto o nível macro (sociedade) (Ferber, 1999).

Os SMA são sistemas compostos por múltiplos agentes, que exibem um comportamento autônomo, mas ao mesmo tempo interagem com os outros agentes presentes no sistema. Estes agentes exibem duas características fundamentais: serem capazes de agir de forma autônoma, tomando decisões levando à satisfação dos seus objetivos; serem capazes de interagir com outros agentes utilizando protocolos de interação social inspirados nos humanos e incluindo, pelo menos, algumas das seguintes funcionalidades: coordenação, cooperação, competição e negociação (Reis, 2003).

O comportamento apresentado pelos agentes para cumprir suas missões normalmente é explicado seguindo dois grandes modelos de funcionamento interno: agentes reativos e agentes cognitivos. Os agentes reativos têm um comportamento muito simples: escolhem suas ações baseados unicamente nas percepções que têm do ambiente. Nos modelos cognitivos, normalmente, os agentes possuem um estado mental e funcionam racionalmente, isto é, raciocinam para construir um plano de ações que levem a um objetivo pretendido (Hübner, 2003).

Para o modelo proposto por (Urban Filho, 2015), cada agente necessita de um grau de individualidade nas emoções a serem sentida e na formação de sua personalidade. Concorrente a isso, é necessário que este mesmo agente desperte a vontade da troca com os outros agentes do meio para sobreviver. Baseado nesta lógica, o modelo de simulação multiagente se torna ideal para desenvolver a aplicação proposta.

No modelo proposto são usados agentes cognitivos, tendo em vista que cada agente possua suas crenças, eles reagirão diferente a cada estímulo. Por exemplo, a cada troca efetuada, sua personalidade e emoções irão mudar para melhor com a troca sendo boa, ou para pior sendo a troca ruim para o agente, fazendo assim que o agente molde sua personalidade e suas emoções para uma diferente avaliação em trocas futuras.

\subsection{Modelos Não-Deterministicos}

A fim de tornar o modelo não-determinístico, foi necessário o estudo de técnicas para a transformação do modelo fixo em não-determinístico, entre os quais foram escolhidos: a Distribuição Normal, a Lógica Fuzzy e a Matemática Intervalar.

\subsubsection{Distribuição Normal}

Segundo Bittencourt and Viali (2006), "em probabilidade e estatística, a distribuição normal é um modelo que descreve o comportamento de vários fenômenos aleatórios".

A distribuição normal é a mais importante das distribuições de probabilidades. Conhecida como a "curva em forma de sino", a distribuição normal tem sua origem associada aos erros de mensuração. É sabido que quando se efetuam repetidas mensurações de determinada grandeza com um aparelho equilibrado, não se chega ao mesmo resultado todas as vezes; obtém-se, ao contrário, um conjunto de valores que oscilam, tal como as emoções e personalidades humanas, de modo aproximadamente simétrico, em torno do verdadeiro valor. Construindo-se o histograma desses valores, obtém-se uma figura com forma aproximadamente simétrica. Gauss deduziu matematicamente a distribuição normal como distribuição de probabilidade dos erros de observação, denominando-a então "lei normal dos erros"(Correa, 2003).

A distribuição normal tem sua função de densidade de probabilidade dada por:

$$
f(x)=\frac{(1 / \sigma \sqrt{2 \pi})}{\exp \left[(x-\mu)^{2} / 2 \sigma^{2}\right]}-\infty<x<\infty
$$

Pela Eq. (1) é possível observar que a distribuição normal inclui os parâmetros $\mu$ e $\sigma$, os quais possuem os significados de posição central da distribuição (média) e dispersão da distribuição (desvio padrão), respectivamente.

Na Fig. 2 são apresentados os parâmetros descritos graficamente em uma curva normal típica.

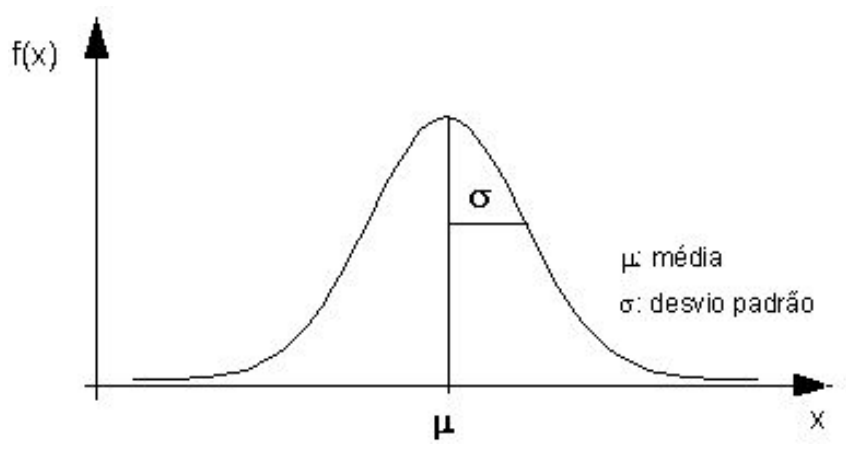

Figura 2: Curva normal típica, apresentando média e desvio padrão

Este método traz uma representação simplificada e de fácil implementação de um modelo nãodeterministico.

\subsubsection{Lógica Fuzzy}

Com a necessidade de lidar com a complexidade dos problemas, a teoria da probabilidade era usada com sucesso em muitas áreas da ciência. Porém, com essa teoria era mais difícil de tratar a incerteza (Mukaidono, 2001).

Diferente da Lógica Booleana, que admite apenas valores booleanos, ou seja, verdadeiro ou falso, a lógica Fuzzy trata de valores que variam entre o e 1 . Deste modo, uma pertinência 0.9 e 0.1 representam quase verdade e quase falso, respectivamente (Silva, 2005).

A lógica Fuzzy é uma técnica capaz de capturar informações vagas, em geral, descritas em linguagem natural, chamadas de variável linguística, e as converter para um formato numérico, de fácil manipulação. Uma variável linguística é uma variável cujos valores 
são nomes de conjuntos fuzzy. Sua principal função é fornecer uma maneira sistemática de aproximação de fenômenos complexos ou mal definidos (Goncalves, 2007). A Fig. 3 apresenta um exemplo onde a temperatura do ambiente é uma variável linguística, assumindo valores frio, normal e quente.

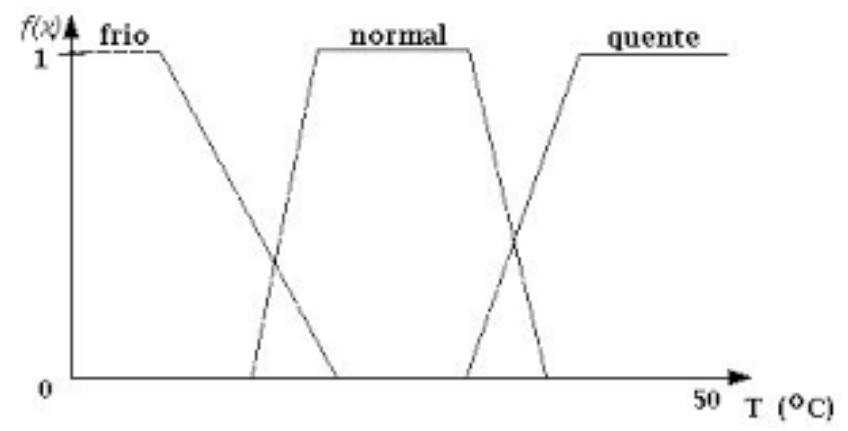

Figura 3: Funções de pertinência para a variável temperatura, utilizando uma função trapezoidal com três valores linguísticos - frio, normal e quente

Segundo Cox et al. (1998), para a aplicação do modelo de lógica fuzzy, é necessário seguir três etapas de raciocínio fuzzy, que são elas: Fuzzificação, Inferência e Defuzzificação.

Na etapa de fuzzificação as variáveis linguísticas são definidas de forma subjetiva, bem como as funções de pertinência. Nesta etapa é englobada pela análise do problema, definição das variáveis, definição das funções de pertinência e criação das regiões.

A inferência fuzzy é um processo de avaliação de entradas com o objetivo de, através das regras previamente definidas e das entradas, obter conclusões utilizando-se a teoria dos conjuntos fuzzy. Esse processo pode ser feito através de modelos de inferência, cuja escolha deve levar em consideração o tipo de problema a ser resolvido, obtendo-se assim um melhor processamento.

E por fim, a etapa de defuzzificação. Nela, as regiões resultantes são convertidas em valores para a variável de saída do sistema, ou seja, corresponde a ligação funcional entre as regiões fuzzy e o valor esperado.

Seguindo os raciocínios fuzzy, este método traz uma melhor visão de como tornar, de modo nãodeterminístico, a influência da personalidade sobre a emoção a ser sentida, definindo assim sua inicialização através de variáveis linguísticas sendo elas: Forte, onde a personalidade influencia muito na emoção; Médio, onde a personalidade influencia moderadamente; e Fraca, onde a personalidade pouco influencia na emoção.

\subsubsection{Matemática Intervalar}

A Matemática intervalar considera um conjunto de métodos para manipulação de intervalos numéricos que aproximam dados incertos. Segundo Oliveira et al. (2001), na Computação Científica os intervalos podem ser aplicados para representar valores desconhecidos e, também para representar valores contínuos. Servem para controlar o erro de arredondamento e para representar dados inexatos, aproximações e erros de truncamento de procedimentos. Estes métodos se baseiam na definição da Aritmética Intervalar e do produto escalar ótimo (Kulisch, 2000). Para Dimuro (1991), resultados intervalares carregam consigo a segurança de sua qualidade e o grau de sua incerteza, pois o diâmetro do intervalo solução é um indicativo da influência dos erros dos dados de entrada e dos erros de arredondamento e truncamento no erro do resultado final obtido.

Para um melhor entendimento do conceito da matemática intervalar, é necessário também ter um entendimento sobre suas operações. Para apresentação das principais operações básicas, sejam $x=\left[x 1 ; x_{2}\right]$ e $y=[y 1 ; y 2] \in \Re$, tem-se as operações aritméticas definidas:

Soma:

$$
X+Y:=\left[x 1 ; x_{2}\right]+[y 1 ; y 2]=[x 1+y 1 ; x 2+y 2]
$$

Subtração:

$$
X-Y:=\left[x 1 ; x_{2}\right]-[y 1 ; y 2]=[x 1-y 2 ; x 2-y 1]
$$

Produto de intervalos:

$$
\begin{array}{r}
X * Y:=\left[x 1 ; x_{2}\right] *\left[y 1 ; y_{2}\right]= \\
{[\min (x 1 * y 1, x 1 * y 2, x 2 * y 1, x 2 * y 2) ;} \\
\max (x 1 * y 1, x 1 * y 2, x 2 * y 1, x 2 * y 2)]
\end{array}
$$

Divisão de intervalos:

$$
\begin{array}{r}
X / Y:=\left[x 1 ; x_{2}\right] /\left[y 1 ; y_{2}\right]=\left[x 1 ; x_{2}\right] *[1 / y 2 ; 1 / y 1] \\
(\text { se } 0 \notin[y 1 ; y 2]) ;
\end{array}
$$

Através do estudo sobre o modelo de matemática intervalar, por trabalhar com um intervalo de números reais ao invés de um único número fixo e a utilização das operações básicas, será possível tornar o modelo proposto por (Urban Filho, 2015) não-determinístico, fazendo com que assim a personalidade possua sempre um intervalo de valores referente ao grau de influência ao sentimento da emoção.

\section{Modelo Base}

Nesta seção é apresentado o modelo proposto por Urban Filho (2015), que foi utilizado como modelo base para o desenvolvimento deste trabalho.

Primeiramente, é necessário compreender o modelo comportamental do agente, onde define-se em três partes, as quais são dependentes umas das outras. A 
parte das ações é responsável por determinar qual ação o agente tomará a partir de seus recursos e sua personalidade. Baseados no modelo OCC, as emoções são responsáveis por serem geradas e sentidas a partir das consequências anteriores. E para fechar o ciclo do modelo comportamental, a parte da personalidade, que é responsável pela atualização dos pesos OCEAN, nele a partir das emoções sentidas, são calculados os novos fatores OCEAN.

Para a validação desse modelo comportamental de um agente, foi necessário criar um sistema multiagente. E para que fosse testado, foi criado um modelo de mundo no qual os agentes serão inseridos. Este modelo é responsável pelas regras de sobrevivência e de trocas para cada agente. Um diagrama mais detalhado do modelo comportamental está representado na Fig. 4.

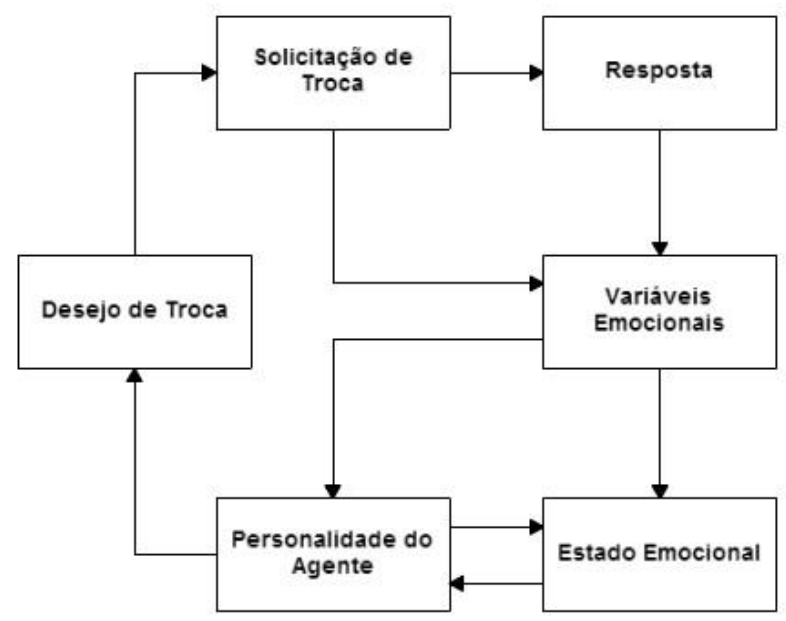

Figura 4: Diagrama detalhado do comportamento do modelo (Urban Filho, 2015), onde as etapas são apresentadas, bem como suas interligações

\subsection{O modelo para gerar emoções}

Utiliza-se como base o modelo proposto por (Egges et al., 2004). O modelo apresenta uma variação de emoções de acordo com a personalidade. O diagrama da Fig. 5 apresenta o comportamento do modelo, onde o desejo emocional do agente é definido pela percepção do agente e a emoção sentida através da personalidade e do desejo emocional do agente.

No modelo foram definidas variáveis para um melhor entendimento do modelo: um vetor de pesos de personalidade $P$ de tamanho $N p$ e um estado emocional ee de tamanho $\mathrm{Ne}$, onde $\mathrm{Np}$ é o número de fatores de personalidade que se deseja simular. No modelo é utilizado um tamanho de cinco para $N p$, que indica a quantidade de fatores de personalidade OCEAN, Ne é o número de emoções que se deseja simular. No modelo são utilizadas vinte e duas emoções, essas definidas pelo modelo OCC, e ambas com seus valores entre o intervalo $[0,1]$.

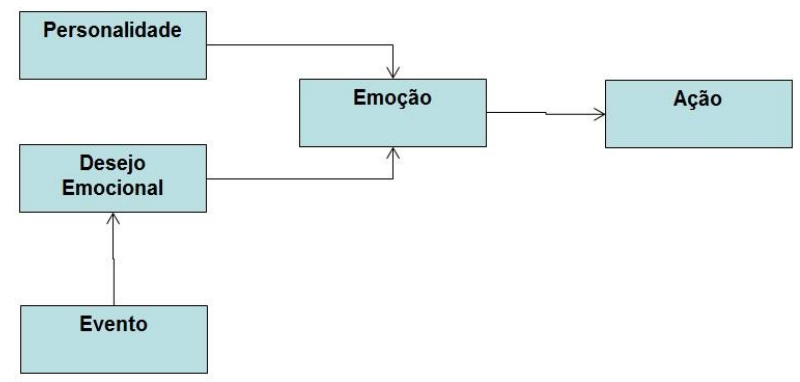

Figura 5: Diagrama do comportamento do modelo (Urban Filho, 2015), detalhando com as emoções são geradas e sua atuação sobre as ações do agente

O vetor ee é responsável por descobrir qual emoção será sentida no instante $t$. Sendo que no instante $t=0$, os valores de suas componentes serão nulas.

Outra variável essencial para o modelo é a de desejo emocional $d E$, de tamanho $N e$, a qual será diretamente relacionada com os resultados das ações que ocorrem com o agente, ou seja, seus valores são definidos de acordo com a percepção do agente sobre o resultado de suas ações, também representada por valores no intervalo $[0,1]$.

Tendo esses três vetores do modelo, deve-se entender como o vetor de estado emocional varia em função do vetor de personalidade. Duas outras componentes são necessárias para realizar tal variação: a matriz de pesos de influência de variação, chamada de $M E P$ e um vetor que armazena o valor dos pesos desta matriz com os pesos OCEAN, chamado de iP.

A matriz MEP possui um tamanho Ne x Np. Essa matriz é responsável pela influência da personalidade nas emoções, pois cada componente tem um peso referente a quanto uma dada personalidade influencia em uma dada emoção. Os pesos desta matriz estão compreendido no intervalo [0;1]. Nesse modelo base, essa matriz possui sua inicialização fixa.

$\mathrm{O}$ vetor $i P$, de tamanho $N e$, é responsável por armazenar o quanto a personalidade do agente naquele instante, e influencia na emoção que será sentida. Este vetor é obtido através do resultado do produto entre $M E P$ e $P$, visto na Eq. (6).

$$
i P=M E P * P
$$

Após ter obtido a influência que a personalidade tem nas emoções a serem sentidas e tendo também o desejo emocional, é preciso determinar qual emoção tem mais chance de ser ativada no agente. Para isto, foi definido o último vetor presente nesta etapa, chamado de $i E$.

$\mathrm{O}$ vetor $i E$ possui o tamanho $\mathrm{Ne}$, e representa o estado emocional do agente no instante $t$, representado pelo produto entre o vetor iP e $d E$ vistos na Eq. (7). Os pesos desse vetor estão presentes no intervalo [0;1].

$$
i E=i P * d E
$$


O cálculo do estado emocional ee presente na Eq. (8) ocorre pela variação do estado emocional anterior ee(t1), com a variação emocional no instante atual (iE) e um peso constante de decaimento da função, chamado de $d C$, de tamanho Ne.

$$
e e=e(t-1)+i E-d C
$$

O fluxograma na Fig. 6, apresenta, de forma resumida, o comportamento do modelo, mostrando o fluxo das variáveis que compõem as equações, assim como suas dependências.

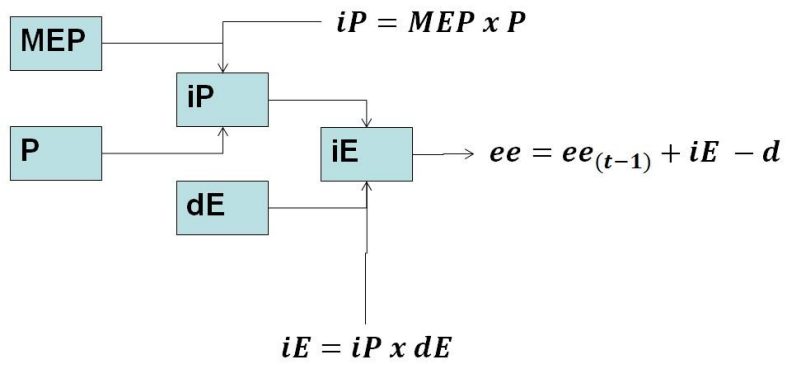

Figura 6: Fluxograma das equações do modelo de emoções (Urban Filho, 2015), apresentando onde as Eqs. (6) a (8) são aplicadas

\subsection{O modelo para atualização da personali- dade}

Para atualizar as personalidades é necessário verificar a emoção sentida naquele instante de tempo e em quais pesos OCEAN esta emoção influencia. Após, é feito um cálculo de atualização que utiliza como base o peso da personalidade no instante anterior.

Para o entendimento da atualização de personalidade é necessário, primeiramente, saber que a variação de cada peso OCEAN pode ser representado no intervalo [0;1], onde 0 significa a abstinência de um determinado peso e 1 a total presença.

Caso um agente tenha um peso OCEAN com o valor próximo aos limites (o ou 1), a variação de sua personalidade é menor que quando seu peso é intermediário, ou seja, um agente com $\mathrm{N}=0,1$ tem menos variação positiva em seu peso OCEAN do que um agente com $\mathrm{N}=0,6$, quando expostos à um mesmo evento de Neuroticismo.

Para que possa ocorrer este comportamento de variação, os valores OCEAN foram definidos por funções sigmoidais, possibilitando assim esta variação maior quando seu peso é médio, e menores variações quando seus pesos tendem aos limites (o ou 1).

Na Eq. (9) é mostrada a representação dos pesos OCEAN e a Fig. 7 apresenta seu comportamento.

$$
f(x i)=\frac{1}{1+e^{-k x}}
$$

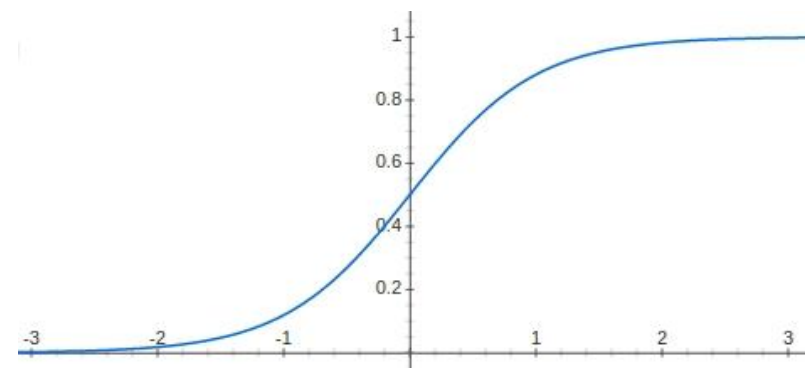

Figura 7: Curva gerada pela Eq. (9) utilizando $\mathrm{k}=2$

São definidas duas equações para a atualização do peso OCEAN: uma define o comportamento de subida e a outra o comportamento de descida de cada peso OCEAN. Nas equações são apresentados dois fatores de personalidade, a personalidade social $f(x)$ e a biológica pBio.

Diferente da personalidade social, a personalidade biológica nunca muda, ela é constante durante toda vida do agente e é responsável por fazer com que um indivíduo seja propenso a ter certos comportamentos. No modelo proposto, ela é responsável por influenciar a personalidade final do agente. Ou seja, um agente que tenha sua personalidade biológica definida como egoísta, por mais altruísta que sejam as interações que este agente sofra ao longo da vida, nunca será completamente altruísta. No modelo base, é necessário inicialmente que sejam setados esses dois vetores. Para a personalidade biológica, todo vetor foi definido com o valor de 0,5 . Já para a personalidade social deve-se definir o desejo do usuário, com o intuito de realizar os testes nas simulações.

As equações Eqs. (10) e (11) representam, respectivamente, as equações de comportamento de subida e de descida. Elas possuem uma constante de divisão, para que a mudança em $x$ ocorra de forma suavizada, chamada de $f D$ e no modelo base utiliza-se o valor de duzentos e cinquenta (250), e uma constante fT que representa o fator temporal. A cada iteração esse fator temporal aumenta, diminuindo cada vez mais a variação sofrida por $x$. Possui a função de dar um peso para emoções sentidas anteriormente, fazendo assim que essa emoção sentida anteriormente continue tendo um peso, mesmo que pequeno, na personalidade atual do agente. Ou seja, como nos seres humanos, uma emoção anteriormente sentida deixará uma marca pelo resto da vida do agente. Outra constante de multiplicação é a $C$, responsável por definir o quanto a personalidade biológica irá influenciar no cálculo de atualização de personalidade. No modelo base, essa constante possui o valor dois (2).

$$
x(t+1)=x+\frac{f(x)+C *(p B i o-f(x))}{f D+f T}
$$




$$
x(t+1)=x-\frac{f(x)+C *(p B i o-f(x))}{f D+f T}
$$

\subsection{Modelo Multiagente}

Nesta seção é apresentado o modelo utilizado como base e seu conjunto de regras no sistema multiagente, bem como o modo que os agentes despertam o desejo de troca e os resultados das ações e emoções sentidas.

\subsubsection{Conjunto de Regras}

Foi desenvolvido um modelo para simplificar ao máximo as ações e demonstrar de maneira clara como a personalidade pode influenciar nas ações de um agente.

Para este fim, o modelo desenvolvido é baseado em trocas entre os agentes. Este modelo consiste na obtenção de recursos para cada agente e o consumo destes recursos, fazendo com que um agente que não tenha recursos para consumir, morra.

Segundo Urban Filho (2015):

\begin{abstract}
Em uma cidade existem apenas pequenos agricultores e cada agricultor produz apenas um determinado alimento. Um agricultor pode consumir o que produz. Entretanto, para ter uma melhor saúde, ele deve variar sua dieta, pelo menos uma vez por semana. Como cada agricultor pode produzir apenas um tipo de recurso, ele deve realizar trocas com outros agricultores de sua cidade.
\end{abstract}

Assim, é definido o ambiente proposto, onde cada agricultor é representado por um agente e cada 'cultivo' é representado por um tipo de recurso. Deste modo, foram definidas as seguintes regras:

i. Se um agente não consumir um recurso diferente dentro de um número $N$ de dias, ele morre;

ii. Após consumir um recurso diferente, o agricultor tem mais $N$ dias para consumir outro recurso diferente novamente;

iii. A produção de recurso $(P R)$ de cada agente deve ser de pelo menos $N$ recursos para cada $N$ dias, a fim de a cada dia poder ser consumido um recurso, próprio ou trocado;

iv. Um agente só pode fazer uma solicitação de troca a cada dia, entretanto pode receber mais de uma solicitação;

v. Deve existir um valor $M$, que defina a quantidade máxima de estoque para cada recurso.

No modelo base, o $N$ possui o valor quatro e o $P R$ possui o valor de 8 . Assim, a cada 4 dias, os agentes produzem 4 recursos a mais para efetuarem a troca e obterem um novo recurso para consumo.

\subsubsection{Desejo de troca}

Primeiramente, é demonstrado como ocorre a escolha de uma ação. Após é demonstrado como a resposta desta ação influencia na emoção sentida.

O modelo base utiliza-se da metodologia Prometheus, que é uma metodologia para Engenharia de Software Orientada a Agentes, nele é modelado um agente com suas crenças, ações e planos, como pode ser visto na Fig. 8.

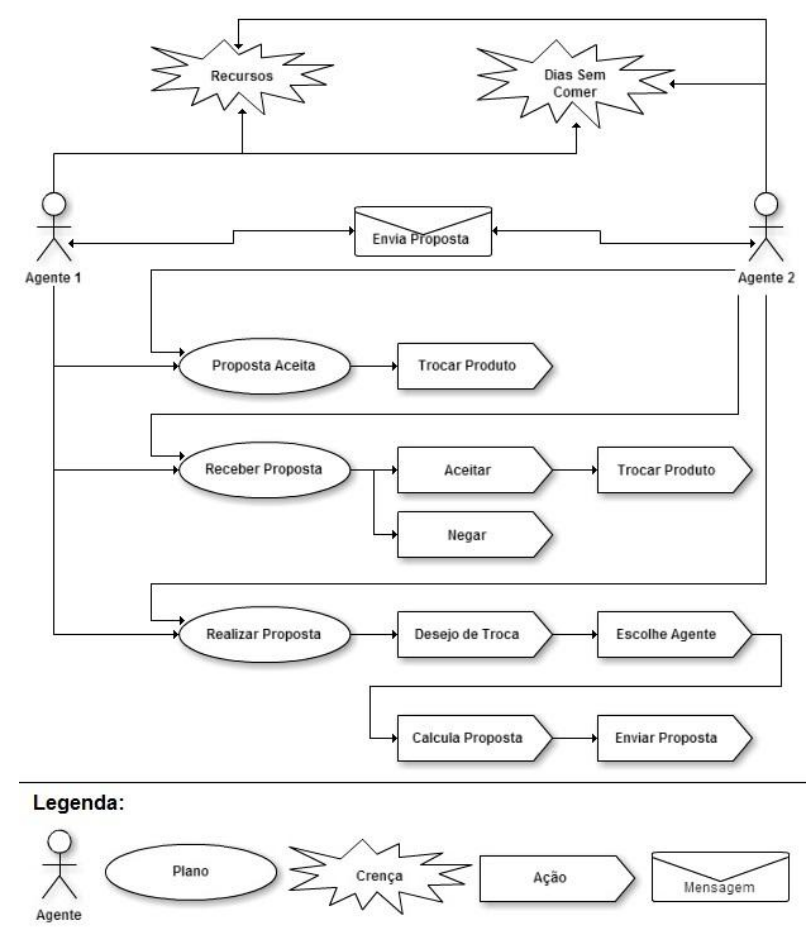

Figura 8: Crenças, planos e ações dos agentes (Urban Filho, 2015) segundo a metodologia Prometheus

Para definir se um agente tem ou não o desejo de realizar uma troca, existem duas crenças: uma que representa a quantidade de dias sem comer um recurso diferente e outra a quantidade de cada recurso que o agente tem naquele momento. As escolhas das ações são baseadas nestas duas crenças e em seus pesos de personalidade.

Uma solicitação de troca sempre será realizada quando o agente tem um desejo de troca. Esse desejo é definido pela necessidade que o agente tem de conseguir um novo recurso, ou seja, os dias que ele ainda tem para consumir e a quantidade de recursos extras que ele possui guardado.

Tudo depende do nível de Conscientiousnness e de Extrovert do agente, isso quer dizer que para o agente ter o desejo de troca, ele deve estar focado em alcançar o seu objetivo (Conscientiousnness) e o quanto ele tem de facilidade em se comunicar com os outros agentes em sua volta (Extrovert). Contudo, se houver um desejo de troca, será necessário escolher um agente para a troca e definir a oferta a ser proposta.

A escolha do agente para realizar a troca é definida por três fatores: o primeiro é o peso Openness, que indica o quanto ele está aberto a uma tentativa de troca com o outro agente; segundo, o peso Neuroticism, que indica o nível de medo que o agente possui da troca dar certo ou não; e por fim, um peso da sua última troca efetuada, caso já tenha efetuado alguma troca anteriormente. Esse último peso serve para verificar 
se as trocas anteriores foram boas. Sendo boas, haverá um peso maior para que que não mude de agente a ser solicitado a troca. Sendo ruins, ele terá maior chance de escolher um agente diferente.

A oferta será calculada com base na necessidade e no Agreableness do agente, pois quanto maior for a necessidade do agente, mais recursos ele irá ofertar para o outro agente. Da mesma forma, quanto mais altruísta o agente for, mais se importará de realizar uma oferta boa para o outro agente.

Após serem definidos os valores de troca, é enviada uma solicitação de troca para o agente ao qual será solicitada a troca. $\mathrm{O}$ agente que envia a proposta denomina-se $A g_{1}$, e o que recebe de Ag2. Esta solicitação serve para verificar se o Ag2 está ocupado, já efetuando alguma troca. Uma vez que Ag2 está livre, é enviada uma mensagem indicando a oferta proposta, ou seja, quantos recursos de $A g 1$ por quantos recursos de Ag2. Esta ação será responsável pela primeira parte para gerar as emoções, a qual é apresentada no fluxograma da Fig. 9.

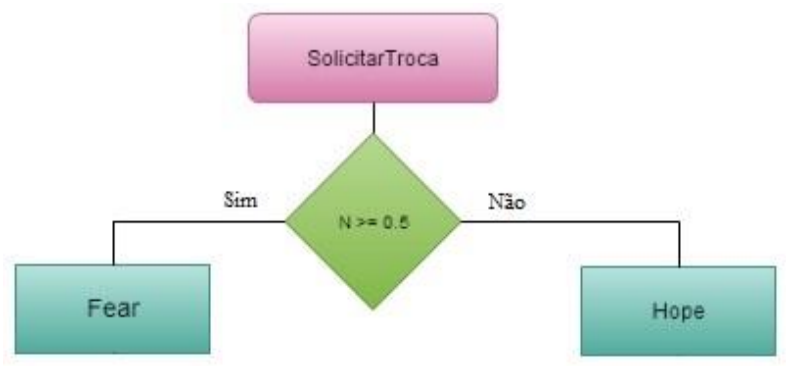

Figura 9: Fluxograma para as emoções de expectativa de (Urban Filho, 2015), onde dependendo do Neuroticism do agente, poderá expressar Medo (Fear) ou Esperança (Hope)

Quando Ag2 receber a proposta, ele irá avaliar se ela é boa ou não. A avaliação da proposta é feita através de dois parâmetros: o Agreeableness de $\mathrm{Ag}_{2}$, pois se ele tiver um alto nível de altruísmo, ele tentará ajudar o outro agente, aceitando a troca; e também através da verificação de quanto boa é a oferta de $A g 1$, verificando se está ganhando ou perdendo recursos com a mesma. Se o Ag2 aceitar, eles irão trocar os recursos. Esta etapa será responsável por gerar a segunda parte das emoções sentidas pelo agente, a terceira e a quarta parte são introduzidas na próxima seção.

\subsubsection{O resultado das ações e as emoções sentidas}

Para uma emoção ser gerada é necessário que o agente execute alguma ação e essa ação seja responsável pela geração das emoções é a solicitação de troca. Esse procedimento de geração de emoções é dividido em quatro etapas.

A primeira etapa, já foi mostrado na seção anterior, ocorre quando o Ag1 fizer a solicitação de troca, envolvendo assim as emoções de expectativa. Dentre as emoções de expectativa encontram-se Hope e Fear. $\mathrm{O}$ sentimento dessas emoções estão diretamente relacionadas com o nível de Neuroticism do Ag1. Ou seja, se o $A g_{1}$ for neurótico, ele sentirá medo de $A g_{2}$ e não aceitará a troca. Caso o contrário, ele sentirá esperança por $A g_{2}$ e aceitará sua troca. Este comportamento é apresentaado no fluxograma da Fig. 9.

A segunda etapa é composta por quatro emoções: Satisfaction, Fears-Confirmed, Relief e Disapointment, que são chamadas de emoções de realização, onde Satisfaction e Disapointment correspondem as consequências de Hope, e Fears-Confirmed e Relief correspondem as consequências de Fear, quando a troca é aceita ou não, respectivamente por Ag2. A Fig. 10 apresenta o fluxograma com estas emoções.

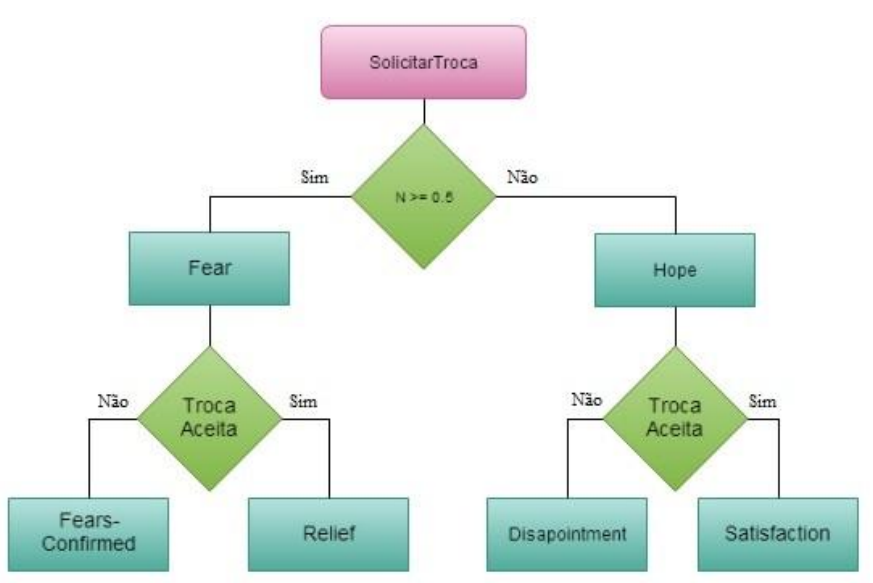

Figura 10: Diagrama para as emoções de realização (Urban Filho, 2015), onde dependendo do Neuroticism e da aceitação das trocas poderá sentir Fears-Confirmed, Relief, Disapointment ou Satisfaction

Por fim, a terceira e quarta etapa, são chamadas de emoções de avaliação. Estas emoções são geradas após o agente analisar se ele efetuou uma boa troca ou não. Na terceira etapa, são geradas emoções de avaliação para o próprio agente. Essas emoções são: Joy, Distress, Gloating, Ressentment, Admiration, Reproach, Gratification, Remorse, Gratitude e Anger, as quais são influenciadas pelos pesos OCEAN e pela aceitação ou rejeição da oferta por Ag2. A Fig. 11 apresenta o fluxograma referente a esta etapa.

Na quarta etapa, são geradas emoções de avaliação para o outro agente. Estas emoções são: Happy-For, Pitty, Pride e Shame, as quais são influenciadas pela proposta feita para $A g_{2}$, se a troca for ruim para ele ou não. A Fig. 12 apresenta o fluxograma desta etapa.

Ao verificar estas emoções, elas serão colocadas no vetor de influência emocional (iE), e será calculada qual emoção será sentida.

\section{Implementação dos Modelos Não- determinísticos}




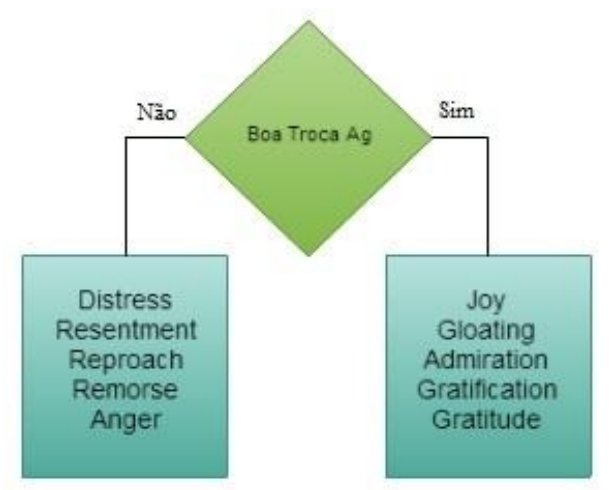

Figura 11: Fluxograma para as emoções de avaliação primeiro agente (Urban Filho, 2015), onde dependendo se a troca foi considerada boa apresentará grupos de emoções diferentes

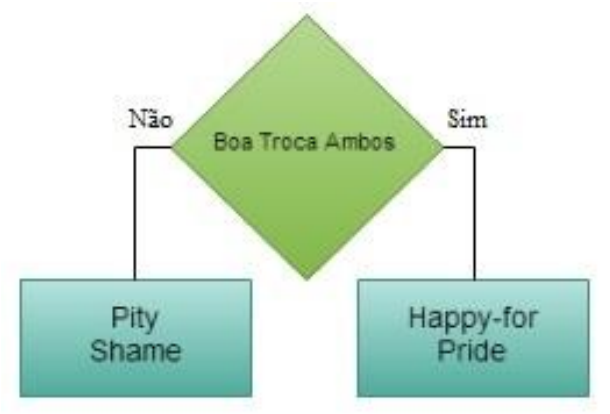

Figura 12: Fluxograma para as emoções de avaliação segundo agente (Urban Filho, 2015)onde dependendo se a troca foi considerada boa apresentará grupos de emoções diferentes

\subsection{Distribuição normal}

A partir de estudos realizados sobre a distribuição normal, descobriu-se que ela apresenta uma fórmula para o cálculo de sua densidade de probabilidade, apresentados na Eq. (1), onde através de cálculos realizados pela equação é possível determinar um valor em um intervalo, pois ela necessita da média, ou seja, o termo que encontra-se no meio do intervalo e o desvio padrão, que nele é mostrado o tamanho do intervalo.

Essa equação foi implementada na matriz de influência de personalidade sobre as emoções (MEP), em sua inicialização é feito o cálculo da densidade de probabilidade utilizando-se o valor definido no modelo base como a média, e o desvio padrão. Em cada simulação será utilizado um valor diferente de desvio padrão, que será melhor explicado na análise de resultados. Os resultados desses cálculos matemáticos criarão uma nova matriz MEP.

Observando este modelo, é possível concluir que se trata de um modelo de fácil implementação e assim tornando o modelo com saídas pouco variáveis a cada execução do algoritmo.

\subsection{Lógica Fuzzy}

Para a implementação da lógica fuzzy no modelo base, primeiramente é necessário uma análise do problema, definição das funções de pertinência e a criação das regiões compreendidas na etapa de fuzzificação.

Existem várias formas de números fuzzy. Mas, para o modelo proposto, é utilizado o número fuzzy triangular, apresentado na Fig. 13 e representado por três pontos expresso por $(a, m, b)$. Esta representação é interpretada como funções de pertinência, apresentadas na Eq. (12).

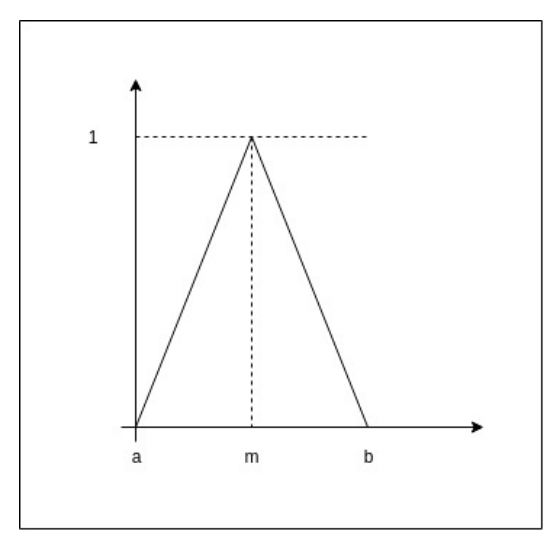

Figura 13: Exemplo de uma função Fuzzy triângular, apresentando os os valores de $m, a$ e $b$ presentes na Equação 12

$$
\left\{\begin{array}{l}
0, \text { se } x<a \\
\frac{x-a}{m-a} \text {, se } a<x \leq m \\
b-x, \text { se } m<x \leq b \\
b-m \text { se } x \geq b
\end{array}\right.
$$

Seguindo o modelo de números fuzzy triangular, foram definidas suas variáveis linguísticas, sendo elas: Baixo, Médio e Alto, como mostrado na Fig. 14. Essas variáveis são responsáveis por três regiões: baixo está compreendida no intervalo de [0;0.4], tendo sua função de inferência apresentada na Eq. (13); médio está compreendida no intervalo $[0.2 ; 0.8]$, tendo sua função de inferência apresentada na Eq. (14); e alto compreendida no intervalo entre [0.6;1], tendo sua função de inferência apresentada na Eq. (15). O intervalo médio é maior que os outros demais, baixo e alto, pois foi levado em consideração que as pessoas em sua maioria possuem por natureza traços de personalidade medianos.

$$
\left\{\begin{array}{l}
0, \text { se } x<0 \\
\frac{x-0}{0.2-0} \text {, se } 0<x \leq 0.2 \\
\frac{0.4-x}{0.4-0.2} \text { se } 0.2<x \leq 0.4 \\
0, \text { se } x \geq 0.4
\end{array}\right.
$$




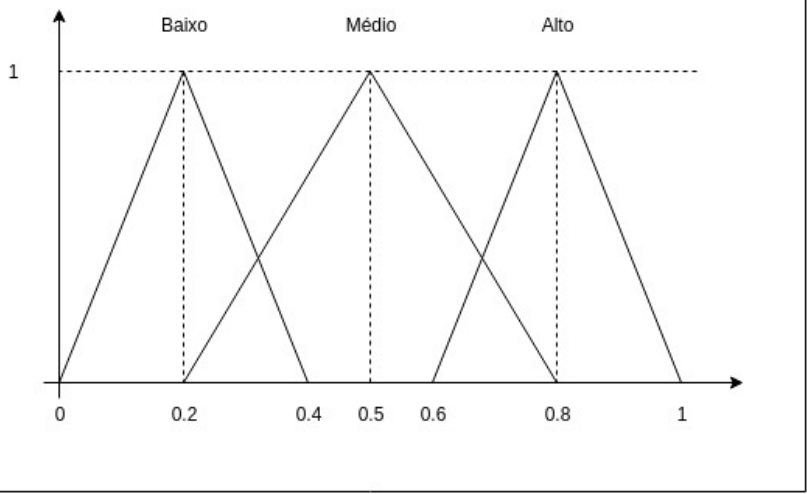

Figura 14: Definição do modelo triangular Fuzzy proposto neste trabalho, onde tem-se três variáveis linguísticas - baixo, médio e alto

$$
\left\{\begin{array}{l}
0, \text { se } x<0.2 \\
\frac{x-0.2}{0.5-0.2}, \text { se } 0.2<x \leq 0.5 \\
\frac{0.8-x}{0.80 .5}, \text { se } 0.5<x \leq 0.8 \\
0, \text { se } x \geq 0.8
\end{array}\right.
$$

$$
\left\{\begin{array}{l}
0, \text { se } x<0.6 \\
\frac{x-0.6}{0.8-0.6}, \text { se } 0.6<x \leq 0.8 \\
\frac{1-\bar{x}}{1-0.8}, \text { se } 0.8<x \leq 1 \\
0, \text { se } x \geq 1
\end{array}\right.
$$

Depois de definidas as funções de pertinência e as regiões, o próximo passo é calcular o valor resultante do processo de lógica fuzzy, etapa chamada de desfuzzificação. Nesse modelo não-determinístico serão utilizados os valores da matriz $M E P$, como centro do intervalo, o tamanho desse intervalo. Esse segundo parâmetro será definido de acordo com o objetivo da simulação (na seção de análise de resultados será melhor explicado). Dentro destes intervalos será escolhido randomicamente um valor, sendo este o valor utilizado nas funções de inferência.

Calculando as três funções de inferência serão obtidos três valores de saída, o valor de baixo, o de médio e o de alto. Como resultado final para esse modelo proposto será utilizado o valor de máximo definido por MAMDANI (Mukaidono, 2001), onde é utilizado o maior valor entre os três gerados como saída. Este novo valor fará parte, até o final da execução, do modelo da nova matriz MEP. Por exemplo, caso o valor sorteado seja 0.3 , ele passará pela função de inferência baixo, médio e alto obtendo respectivamente os valores de $0.5,0.5$ e 0 . Utilizando-se a função de Mamdani de valor máximo, o valor a ser utilizado na matriz MEP será o valor de 0.5 .

\subsection{Matemática Intervalar}

Através de estudos sobre a matemática intervalar foi possível escolher o melhor modo para sua implementação no modelo proposto. A implementação no modelo ocorreu de modo que os valores da matriz MEP original são utilizados para ser o valor médio do intervalo construído. O tamanho do intervalo varia de acordo com o objetivo da simulação (será melhor explicado na análise dos resultados). Assim, estes intervalos serão os novos índices da matriz $M E P$.

Deste modo, a cada consulta a matriz $M E P$, um novo valor do intervalo presente no índice da matriz será escolhido para os cálculos de atualização do estado emocional do agente no instante $t$.

Por exemplo, utilizando um intervalo do tamanho de 0,2 e o índice da matriz anteriormente era o valor de 0,6 . O novo índice da matriz MEP será o intervalo de $[0,5 ; 0,7]$. Deste modo, será escolhido qualquer valor deste intervalo para os cálculos de atualização do estado emocional.

Assim é possível observar que a matemática intervalar possui uma grande capacidade de nãodeterminismo, trabalhando seus cálculos com intervalo de valores ao invés um único valor.

\section{Análise dos resultados}

Para uma melhor explicação da análise de resultados ela foi dividida em duas etapas. A primeira etapa apresenta a configuração do ambiente multiagente e a segunda etapa apresenta a análise e comparação dos resultados.

\subsection{Configuração do Ambiente Multiagente}

Assim como no modelo base, o ambiente multiagente conta com a utilização de 4 agentes distintos. Cada simulação contém 10.000 dias, onde só uma troca de recurso pode acontecer por dia, sendo ela boa ou ruim. Com o intuito de obter a média de dias em que os agentes se mantiveram vivos, foram realizadas 100 simulações desses 10.000 dias, obtendo assim uma simulação completa do modelo. Com o propósito de obter uma maior quantidade de resultados, essa simulação completa foi realizada mais cinco vezes para cada cenário.

Para as simulações foram propostos dois ambientes de simulações: um ambiente hostil e um ambiente propício. No ambiente hostil os agentes possuem valores baixos de OCEAN, exceto o Neuroticism. Por exemplo, um agente inicializa com os valores de OCEAN $a g[0](0,1 ; 0,1 ; 0,1 ; 0,1 ; 0,9)$. No ambiente propício é o contrário, os agentes inicializam com os valores altos de OCEAN, exceto o Neuroticism. Por exemplo, um agente inicializa com os valores OCEAN $a g[0](0,9 ; 0,9 ; 0,9 ; 0,9 ; 0,1)$.

Nestes dois ambientes multiagente propostos, um dos agentes (no caso, o agente escolhido foi o Ago) será o agente a ser monitorado, ou seja, no ambiente propício ele inicializará com os valores de OCEAN hostil e da mesma forma, no ambiente hostil ele inicializará com os valores OCEAN propício. Deste modo, será pos- 
Tabela 3: Configuração Ambiente Propício

\begin{tabular}{|l|l|l|l|l|l|}
\hline Agente & O & C & E & A & N \\
\hline Agente 0 & 0.1 & 0.1 & 0.1 & 0.1 & 0.9 \\
\hline Agente 1 & 0.9 & 0.9 & 0.9 & 0.9 & 0.1 \\
\hline Agente 2 & 0.9 & 0.9 & 0.9 & 0.9 & 0.1 \\
\hline Agente 3 & 0.9 & 0.9 & 0.9 & 0.9 & 0.1 \\
\hline
\end{tabular}

sível verificar a adaptação do agente em um ambiente diferente do dele.

Em todos os casos de teste, a personalidade biológica ( $p$ Bio) foi mantida com valores iguais aos propostos por (Urban Filho, 2015), onde todos os valores OCEAN serão mantidos no valor de 0,5 . Assim, a personalidade biológica influenciará igualmente todos os valores OCEAN da personalidade social ( $p$ Social).

Nos modelos não-determinísticos: distribuição normal, lógica fuzzy e matemática intervalar foram utilizados três diferentes tamanhos de intervalos com o intuito de analisar a variação dos agentes. São eles: 0,1 , 0,2 e 0,5 .

Cada valor de intervalo foi escolhido com um propósito. O intervalo 0,1 foi escolhido por ele ter uma variação pequena e assim ser muito parecido com o modelo original, proposto por (Urban Filho, 2015), podendo assim ter uma visão de quanto esta pequena variação é capaz de mudar o modelo. O intervalo de 0,2 foi escolhido por ser um pouco maior que o primeiro intervalo e assim, ele já se distancia do modelo original aumentando assim o não-determinismo. $\mathrm{O}$ último intervalo escolhido, 0.5 , tem o objetivo de ser 0 mais impreciso de todos, e assim, poder mostrar que quanto mais inconstante é um agente, mais randômico são seus resultados.

\subsection{Análise e Comparação dos Resultados}

Com o intuito de analisar e comparar o comportamento do agente monitorado, neste caso o agente Ago, foram realizadas cinco simulações completas de cada técnica para a obtenção dos resultados da média de dias que o agente se manteve vivo.

O resultado das cinco execuções completas de cada técnica foi representado graficamente através da técnica de box plot ${ }^{1}$.

A Tabela 3 apresenta como o ambiente propício foi configurado. Neste ambiente, os agentes que não serão monitorados, 1, 2 e 3, inicializam com os fatores de personalidade (OCEAN) boas altos, exceto o Neuroticism, que inicializará com o valor baixo. Deste modo, os agentes tendem a querer realizar mais trocas, pelo fato de que o desejo de troca decorra do quanto extrovertido (Extrovert) e quanto concentrado (Conscientiouness) ele é para alcançar os objetivos. Assim, acabam vivendo mais.

A Tabela 4 apresenta como o ambiente hostil foi

\footnotetext{
${ }^{1}$ Box plot é uma ferramenta gráfica para mostrar a variação de valores numéricos por meio dos quartis, possui uma reta que estendese verticalmente a partir da caixa, indicando a variabilidade fora do quartil superior e do quartil inferior, os valores atípicos (valores discrepantes) podem ser plotados como pontos individuais.
}

configurado. Neste ambiente, os agentes que não serão monitorados, 1 , 2 e 3, inicializam com os fatores de personalidade (OCEAN) baixos, exceto o Neuroticism que inicializará com o valor alto. Deste modo, os agentes tendem a querer realizar menos trocas, pelo fato de que o desejo de troca decorra do quanto extrovertido (Extrovert) e quanto concentrado (Conscientiouness) ele é para alcançar os objetivos. Assim, acabam vivendo menos.

Tabela 4: Configuração Ambiente Hostil

\begin{tabular}{|l|l|l|l|l|l|}
\hline Agente & $\mathrm{O}$ & $\mathrm{C}$ & $\mathrm{E}$ & $\mathrm{A}$ & $\mathrm{N}$ \\
\hline Agente 0 & 0.9 & 0.9 & 0.9 & 0.9 & 0.1 \\
\hline Agente 1 & 0.1 & 0.1 & 0.1 & 0.1 & 0.9 \\
\hline Agente 2 & 0.1 & 0.1 & 0.1 & 0.1 & 0.9 \\
\hline Agente 3 & 0.1 & 0.1 & 0.1 & 0.1 & 0.9 \\
\hline
\end{tabular}

Nas Figs. 15 a 17 são apresentados os resultados das médias de dias vividos de cada técnica. Primeiramente, foi feita uma análise de todos modelos entre si: distribuição normal, lógica fuzzy, matemática intervalar e o modelo original proposto por (Urban Filho, 2015). Em seguida, foi feita uma análise individual das implementações dos modelos não-determinísticos, ressaltando os aspectos positivos e os aspectos negativos dos resultados.

Analisando e comparando os resultados obtidos pelas simulações, é possível constatar que em todos ambientes e intervalos, as técnicas não-determinísticas conseguiram fazer com que o agente 0 elevasse a média de dias vividos, pois todas elas obtiveram no primeiro quartil resultados superiores ao do modelo original. Apenas a matemática intervalar, no ambiente propício com o intervalo de 0,5 , teve resultado pior, pois é um modelo que trabalha com um intervalo de números ao invés de um único valor e sendo um intervalo grande, este modelo torna-se muito impreciso e inconstante. Assim, pode-se concluir que a implementação dos modelos não-determinísticos na matriz $M E P$ trouxe uma melhor adaptação do agente Ago ao meio que estava inserido, pois foi constatado que ele teve aumento na média de dias vividos.

A distribuição normal apresentou resultados com uma diferença ao que era esperado. Por ser uma técnica simples e possuir uma grande similaridade com o modelo original, era esperado que seus resultados fossem muito próximo do modelo original. Esta técnica também mostrou que para intervalos pequenos, como 0,1 e 0,2 , mantém praticamente o mesmo intervalo entre o primeiro e o terceiro quartil. Em sua maioria, é notável que com essa técnica obteve-se o maior valor no terceiro quartil, ou seja, foi a técnica que o agente teve a maior média de dias vividos.

A lógica fuzzy mostrou-se nas diferentes simulações, independente do intervalo ou do ambiente, a técnica mais constante. Em praticamente todos os casos, a variação do primeiro para o terceiro quartil se demonstrou pequena, e também o valor no primeiro quartil foi maior que nas demais técnicas. Assim, ela pode representar um ser humano estável, que independentemente do tamanho da variação de humor, mantém-se 

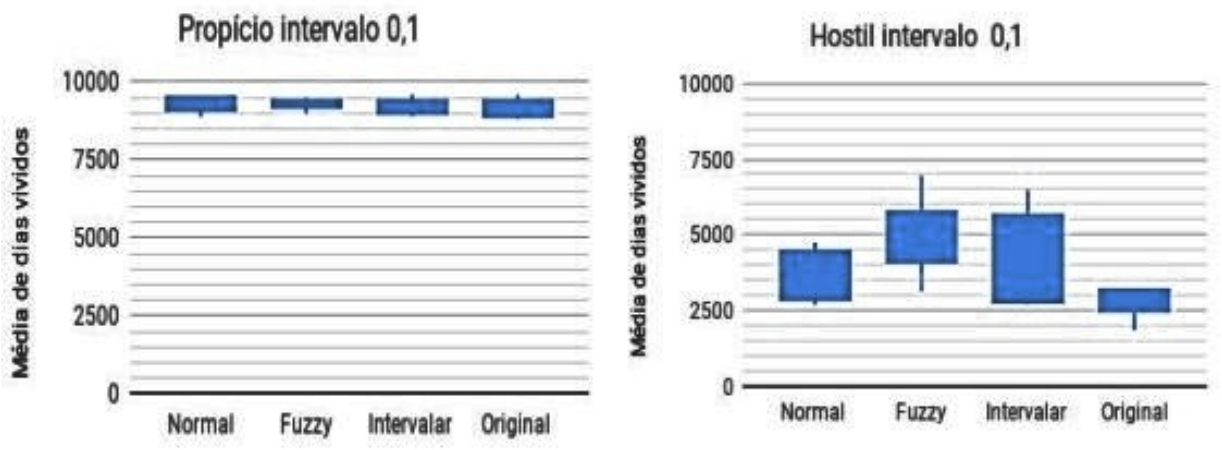

Figura 15: Resultados das médias das iterações por dia vivido de cada uma das técnicas analisadas neste trabalho, com intervalo de $0,1 \mathrm{em}$ ambientes propício e hostil
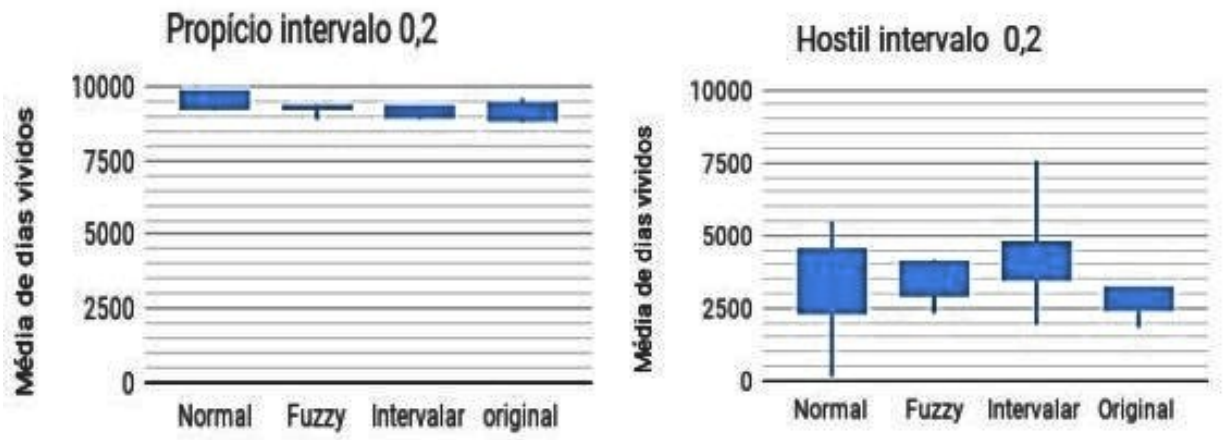

Figura 16: Resultados das médias das iterações por dia vivido de uma das técnicas analisadas neste trabalho, com intervalo de 0,2 em ambientes propício e hostil
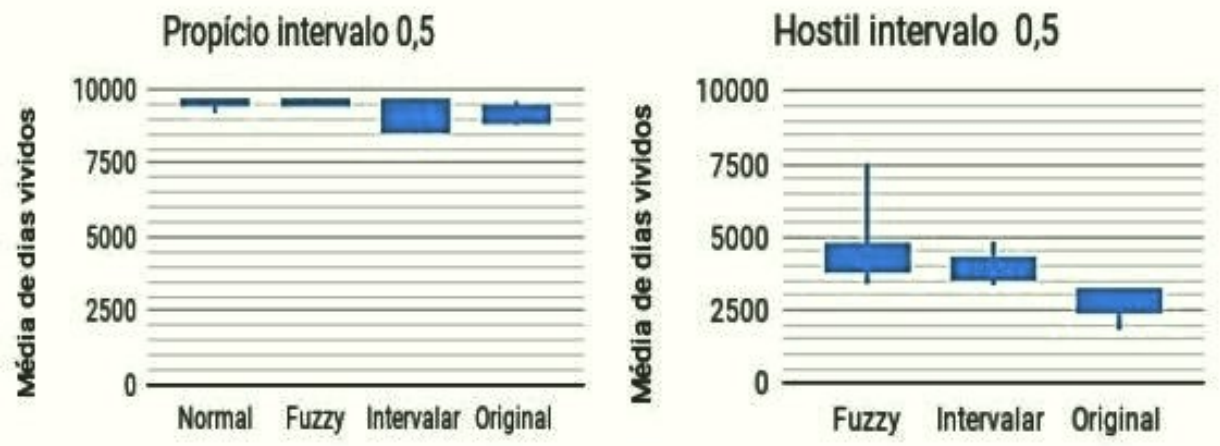

Figura 17: Resultados das médias das iterações por dia vivido de uma das técnicas analisadas neste trabalho, com intervalo de 0,5 em ambientes propício e hostil

com uma variação pequena na média de dias vividos.

Por fim, a matemática intervalar, como previsto, por trabalhar com intervalo de valores, mostrou ser bem inconstante, apresentando variações e resultados completamente diferentes a cada execução. Também foi possível verificar através desta técnica, que quando se aplica um intervalo grande, como 0,5 no ambiente propício, torna-se muito difícil fazer alguma análise, a não ser pelo fato de que o agente se torna muito instável. No ambiente hostil, com o maior intervalo, essa instabilidade em seu humor, faz com que ele tenha a menor perspectiva de vida comparando com os modelos não-determinísticos.

\section{Conclusões e Trabalhos Futuros}

Em nossas vidas, as emoções e personalidades são fundamentais em qualquer tarefa realizada por nós. As emoções possuem um grande impacto na tomada de decisões, ações, memória, atenção, pois elas são consideradas a regra central de nossas vidas (Marsella et al., 2010). A personalidade é o conjunto das características 
marcantes de uma pessoa, é a força ativa que ajuda a determinar o relacionamento das pessoas baseado em seu padrão de individualidade pessoal e social referente ao pensar, sentir e agir (Ekman, 2005). Por sua importância na vida humana, surge o interesse de trabalhar computacionalmente com esses temas.

O modelo proposto por (Urban Filho, 2015, Urban Filho and Adamatti, 2018), por meio de um sistema multiagente, modela as emoções e as personalidades através de modelos já existentes, o modelo OCC para emoções e o modelo OCEAN para personalidades. Nesse modelo, os agentes necessitam realizar trocas de recursos para sobreviver, e o resultado de cada troca influencia em suas emoções e elas na personalidade.

Motivado por esse modelo, surgiu a ideia de torná-lo mais dinâmico, pois ele inicializa sua personalidade e a influência da personalidade sobre as emoções fixa. Com a utilização das técnicas não-determinísticas aplicadas nesse trabalho, foi possível verificar que o agente Ago (que foi o monitorado durante as simulações) teve uma melhor adaptação ao meio que estava inserido (propício ou hostil). Pode-se concluir que das técnicas estudadas, a lógica fuzzy, independente do intervalo ou do ambiente, foi a técnica mais constante, em praticamente todos os casos, a variação do primeiro para o terceiro quartil se demonstrou pequena e também o valor no primeiro quartil foi maior que nas demais técnicas. A distribuição normal, apresentou resultados com muita diferença do esperado, pois é uma técnica simples. Esta possui uma grande similaridade com o modelo original e era esperado resultados parecidos com o modelo utilizado como base, mas mostrou que para intervalos pequenos, como 0,1 e 0,2 , manteve praticamente o mesmo intervalo entre o primeiro e o terceiro quartil e foi a técnica que o agente teve a maior média de dias vividos. A matemática intervalar, por trabalhar com intervalo de valores, mostrou ser bem inconstante, apresentando variações e resultados completamente diferentes a cada execução. Foi possível verificar através desta técnica que quando se aplica um intervalo grande, como 0,5 no ambiente propício, torna-se muito difícil fazer alguma análise, a não ser pelo fato de que o agente se torna muito instável.

Este trabalho focou na aplicação de técnicas nãodeterminísticas na matriz MEP, tornando-a nãodeterminística. Contudo, no modelo proposto por (Urban Filho, 2015) ainda podem ser realizadas algumas alterações:

- Tornar a personalidade social não determinística: atualmente o modelo apresenta a inicialização da personalidade fixa, assim como na matriz MEP. Seria interessante aplicar técnicas não-determinísticas também ao inicializar os valores da personalidade social.

- Executar novas simulações com valores diferentes de 0,5 para a personalidade biológica;

- Testar novos cenários de simulação, não apenas com um ambiente hostil ou propício, mas também com um maior número de agentes interagindo;

- Executar simulações onde mais de um agente seja monitorado no ambiente.

\section{Referências}

Bercht, M. (2001). Em direção a agentes pedagógicos com dimensões afetivas, Tese doutorado, Programa de PósGraduação em Computação da Universidade Federal do Rio Grande do Sul.

Bittencourt, H. R. and Viali, L. (2006). Contribuições para o ensino da distribuição normal ou curva de gauss em cursos de graduação., III Seminário Internacional de Pesquisa em Educação Matemática. Águas de Lindóia - São Paulo .

Carver, C. S. and Scheier, M. F. (2000). Perspectives on personality, Allyn and Bacon.

Correa, S. M. B. B. (2003). Probabilidade e Estatística, PUC MINAS. Disponível em http://estpoli.pbworks. com/f/livro_probabilidade_estatistica_2a_ed.pdf.

Costa, P. T. and McCrae, R. R. (2008). The revised neo personality inventory (neo-pi-r) and neo fivefactor inventory (neo-ffi), in G. J. Boyle, G. Matthews and D. H. Saklofske (eds), The SAGE handbook of personality theory and assessment: Volume 2 - Personality measurement and testing, SAGE Publishing, London, chapter 9, pp. 179-198. http://dx.doi.org/10.4135/ 9781849200479.n9.

Cox, E., O'Hagan, M., Taber, R. and O'Hagen, M. (1998). The Fuzzy Systems Handkbook, Academic Press, Inc.

da Conceicao, M. B. (2009). Comportamento humano no trabalho, Pós-graduação "lato sensu" projeto a vez do mestre, Universidade Candido Mendes.

de Almeida Limeira, D., dos Santos, I. V. and de Oliveira, P. A. (2016). Fundamentação antropológica da educação. Disponível em https://www.webartigos.com/artigos/ fundamentos-antropologicos-da-educacao/139769.

Digman, J. M. (1990). Personality structure: Emergence of the five-factormodel., Annual Review of Psychology 41: 417-440.

Dimuro, G. (1991). Domínios intervalares da matemática computacional, Dissertação de mestrado do programa de pós-graduação em ciência da computação, Universidade Federal do Rio Grande do Sul.

Egges, A., Kshirsagar, S. and Magnenat-Thalmann, N. (2004). Generic personality and emotion simulation for conversational agents, Computer Animation and Virtual Worlds 15(1): 1-13. https://doi.org/10.1002/ cav.3.

Ekman, P. (2005). Basic emotions, in T. Dalgleish and M. J. Power (eds), Handbook of Cognition and Emotion, John Wiley \& Sons, Ltd, chapter 3, pp. 45-60. https: //doi.org/10.1002/0470013494.ch3.

Ferber, J. (1999). Multi-Agent Systems: An Introduction to Distributed Artificial Intelligence, 1st edn, AddisonWesley Longman Publishing Co., Inc., USA. 
Gilbert, N. and Troitzsch, K. G. (2005). Simulation for The Social Scientist, 2 edn, Open University Press, USA.

Goldberg, L. R. (1993). The structure of phenotypic personality traits, American Psychologist 48: 26-34. https://doi .org/10.1037//0003-066x.48.1.26.

Goncalves, A. P. (2007). Aplicação de lógica fuzzy em guerra eletrônica, IX Simpósio de Aplicações Operacionais em Áreas de Defesa (SIGE), Instituto Tecnológico da Aeronáutica. Disponível em https://www.sige.ita. br/anais/IXSIGE/Artigos/A0_07.pdf.

Gratch, J. and Marsella, S. C. (2001). Modeling Emotions in the Mission Rehearsal Exercise, Proceedings of the 1oth Conference on Computer Generated Forces and Behavioral Representation, Orlando, FL, pp. 457-466. Disponível em http://tiny.cc/4c1wmz.

Hübner, J. F. (2003). Um modelo de reorganização de sistemas multiagentes., Tese de doutorado em engenharia elétrica da escola politécnica, Universidade de São Paulo.

Heudin, J.-C. (2018). An emotional multipersonality architecture for intelligent conversational agents, pp. 143-163. https: //doi.org/10.1007/978-3-319-78301-7_7.

Kort, B., Reilly, R. and Picard, R. W. (2001). An affective model of interplay between emotions and learning: reengineering educational pedagogy-building a learning companion, Proceedings IEEE International Conference on Advanced Learning Technologies, pp. 43-46. https://doi.org/10.1109/ICALT.2001.943850.

Kulisch, U. (2000). Advanced arithmetic for the digital computer, design of arithmetic units, Electronic Notes in Theoretical Computer Science 24: 63. https://doi. org/10.1016/S1571-0661(05)80622-X.

Marsella, S., Gratch, J. and Petta, P. (2010). Computational models of Emotion., Oxford University Press.

McDuff, D. and Czerwinski, M. (2018). Designing emotionally sentient agents, Commun. ACM 61(12): 74-83. https://doi .org/10.1145/3186591.

URL: https://doi.org/10.1145/3186591

Millon, T., Weiss, L., Millon, C. and Davis, R. (1994). Millon Index of Personality Styles, TX: The Psychological Corporation.

Mukaidono, M. (2001). Fuzzy Logic For Beginners, Wspc, Singapore.

Oliveira, R., Diverio, A. and Claudio, M. (2001). Fundamentos da Matemática Intervalar, Editora Sagra Luzzato, Porto Alegre.

Ortony, A., Clore, G. and Collins, A. (1988). The Cognitive Structure of Emotions, Cambridge University Press. https://doi.org/10.1017/CB09780511571299.

Pudane, M., Lavendelis, E. and Radin, M. A. (2017). Human emotional behavior simulation in intelligent agents: Processes and architecture, Procedia Computer Science 104: 517 - 524. https://doi.org/10.1016/j. procs. 2017.01.167.
Reis, L. P. (2003). Coordenação em sistemas multiagente: Aplicações na gestão universitária e futebol robótico(coordination in multi-agent systems: Applications in university management and robotic soccer), Tese de doutorado na faculdade de engenharia, Universidade do Porto.

Silva, R. A. C. (2005). Inteligência artificial aplicada a ambientes de Engenharia de Software: Uma visão geral, Universidade Federal de Viçosa.

Tapu, C. S. (2001). Hypostatic Personality: Psychopathology of Doing and Being Made, Ploiesti: Premier.

Tupes, E. and Christal, R. (1961). Recurrent personality factors based on trait ratings., Technical report, Lackland Air Force Base. Technical Report ASD-TR61-97.

Urban Filho, G. A. (2015). Simulação de emoções e personalidades em sistemas multiagente utilizando modelo occ e ocean., Trabalho de conclusão de curso em engenharia de computação, Universidade Federal do Rio Grande.

Urban Filho, G. and Adamatti, D. F. (2018). An adaptive agent approach using personalityand emotions, 2018 XLIV Latin American Computer Conference (CLEI), pp. 215-223. https://doi.org/10.1109/CLEI. 2018.00034. 